\title{
Thermal Decomposition and Flame retardancy of Functional Polyester/Banana Peduncle fibre and Aluminum Hydroxide particle Hybrid Composites.
}

\author{
${ }^{\text {a }}$ E.M Ezeh, ${ }^{\text {a }}$ O.D Onukwuli, , ${ }^{\text {a R.S Odera, }}{ }^{\text {a }}$ V.I. Ugonabo and ${ }^{\mathrm{b}}$ O. Okeke \\ aDepartment of Chemical Engineering, Nnamdi Azikiwe University, Awka, Nigeria \\ bPlastic Production Unit, Scientific Equipment Development Institute, Akwuke, Enugu.
}

\begin{abstract}
Polymers which take up $80 \%$ of the organic industry are known for their high flammability with the production of heat, corrosive toxic gases, and smoke. The need to improve the fire resistance properties of polymer and natural fibre composites lead to the development of functional novel polyester/ aluminum hydroxide (AH) particlesBanana peduncle fibre (BPF) hybrid composites. The composites were produced by varying the ratio of $\mathrm{AH}: \mathrm{BPF}$ from $0: 0,2.5: 2.5,5: 5,7.5: 7.5$ and 10:10wt\%. The thermal and fire properties were determined. The incorporated AH played a crucial role in improving the thermal stability of the composites by acting as effective physical barriers against the thermal decomposition in the polymer composite. There was maximum, endothermic peak, shift to higher temperature, as the weight percent addition of AH was increased, which reflected in improved thermal stability of the composites. This work shows that addition of $10 \mathrm{wt} \% \mathrm{AH}: 10 \mathrm{wt} \% \mathrm{BPF}$ to polyester composite retarded its burning by delaying the ignition time by $22.94 \%$, the end of burning time by $13.15 \%$ and reduction of the total heat release rate by $29.68 \%$.
\end{abstract}

Keywords: Aluminum hydroxide (AH); polyester; flame retardancy; banana peduncle fibres (BPF).

DOI: $10.7176 / \mathrm{CPER} / 62-07$

Publication date: February $29^{\text {th }} 2020$

\subsection{INTRODUCTION}

Fire is a continuous threat to life and property according to fire statistics, more than 12 million fire breaks out every year in the United States, Europe, Russia, and China and Africa Countries killing about 166,000 people and injuring several hundreds of thousands ( Baljinder et al., 2015; Akash Grisha et al., 2017). Polymers which take up to $80 \%$ of the organic chemical industry are known for their flammability with the production of heat, corrosive toxic gases, and smoke. These flame-retardant chemicals called flame-retardants, execute certain specific function(s) during combustion process in order to either extinguish the flame or to slow its propagation (Ali Fazli et al., 2015; Asuke et al.,2016).

Improving the flame retardancy (FR) of polymeric materials is a priority and also a major challenge. According to the National Institute of Standard and Technology (NIST), FR materials can increase the allowable escape time by a factor of 15 , minimizing the heat release by $75 \%$, and enveloping less smoke and toxic gases. The human and economic cost of fire can be significantly reduced by the appropriate use of FR materials and fire protection systems (Boulos et al., 2003).

There has been a considerable interest in the field of flame retardancy as the demand for improved safety in domestic, public, and industrial sectors increased. In recent years, fire retardant (FR) sealants have penetrated markets in building construction because of the requirement for sealing gaps in fire resisting construction applications (Kandare et al., 2010).

Development of ceramic forming filler compounds or combination of compounds, that form an effective thermal barrier under fire conditions could provide a significant improvement in the sealant performance (Abdullah et al., 2013). The manner in which a coherent ceramic structure is formed is important. When the polymer decomposes and vaporizes, loose filler particulates will be remaining and cause the material to disintegrate. However deverification of particular fillers must occur simultaneously with loss of polymer so that the ceramic maintains its shape by fusion of the inorganic particles ( Morgan, 2006; Maria et al., 2012).

Also the developments of fire retardants systems that do not release toxic gases have recently become preferable. For example, the waste electrical and electronic equipment (WEEE) and restriction of hazardous substances (ROHS) directives limt the use of bromine-based flame retardants (Boulos et al., 2003). 
Natural fibres are becoming attractive alternatives to traditional high performance fibres such as glass and carbon fibres for reinforcement in composites (Mohammad et al., 2018). This is because natural fibres are from renewable sources, are biodegradable, and therefore are more environmentally friendly. However, unlike inherently noninflammable glass and carbon fibres, natural fibres thermally degrade and burn readily and their use has been restricted in applications where the fire regulations are stringent (Panigrahi et al., 2002; Sarki et al., 2011 ; Nayra Uranga et al., 2016 ).

The world was a surplus amount of Banana fibres, which has a great potential that can be used as composites material. BPF litter the entire environment which constitute nuisance to the environment, however, the right knowhow (technology) to convert these into engineering materials has remained a daunting challenge to materials engineers in the country. This decision problem sharpens the focus of this research work. Base on the forgoing the research work undertook the development of the use of aluminum hydroxide as flame retardant for polymer/Banana peduncle fibre composites.

\subsection{MATERIALS AND METHOD}

\subsection{Materials}

Peduncles of Miusacavendishi bananas were collected from Banana sellers in Enugu in Enugu State Nigeria. The Banana peduncle fibres were extracted from the banana peduncle and washed with water and dried. The aluminium hydroxide $(\mathrm{AH})$ was used as a flame retardant. The unsaturated polyester resin was used in this research. $2 \%$ solution of cobalt naphthalene and 2\% solution of Methly-ethyl-ketone (MEK) peroxide were used as accelerator and catalyst respectively.

\subsection{Method}

The vinyltriethoxysilane (VTS) and 3-aminoproply triethoxysilane (APTES) solutions were prepared at concentration ( $3 \mathrm{wt} \%$ ) by adding the required type of silane (VTS or APTES) into the mixture of water and ethanol $(20 / 80 \mathrm{wt} \%)$, and then stirred using a glass rod until a complete dissolution was achieved. The fibres were treated with these VTS and APTES solutions for a period 3hours. The polyester resin was converted from a liquid to the solid state by adding hardener, methly ethyl ketone peroxide and symbolized by the (MEKP) and in the form of a transparent liquid. It is added as a unsaturated polyester resin at room temperature, accelerator cobalt mapthalene was used to increase the rate of curing. BPF:AH of 0:0, 2.5:2.5, 5:5, 7.5:7.5 and 10:10wt\% were produced.

The patterns of X-ray diffraction of the composites samples were analyzed with a " $\mathrm{X}$ " pertpro PANalytical, LR $39487 \mathrm{C} \mathrm{XRD}$ diffractometer using CuKa radiation $(\alpha=1.5418 \mathrm{~A})$ at a $34 \mathrm{KV}$ and a current of $25 \mathrm{~mA}$, in a $2 \theta$ angular range between 10 and 90 degrees, making measurements every $0.04^{\circ}$ for $6 \mathrm{~s}$.

Thermal stabilities of the composites were studied using thermogravimetric analyses (TGA). The heating rate of $10^{\circ} \mathrm{C} / \mathrm{min}$ and high purity Argon was continuously passed onto the furnace at a flow rate of $60 \mathrm{ml} / \mathrm{min}$ at room temperature and atmospheric pressure. The TG and DTA curves were obtained from TGA runs using universal analysis 2000 software from TA instrument.

Artificial fire tests were performed on small composite panels using a dual cone calorimeter. Heat flux of $50 \mathrm{~kW} / \mathrm{m}^{2}$ was used because it caused the GRP panel to ignite after heating for 30seconds. It was suggested that the heat flux of $50 \mathrm{~kW} / \mathrm{m}^{2}$ is about the heat energy radiated y a medium intensity room fire (see figure below Abdullah et al., 2013) 


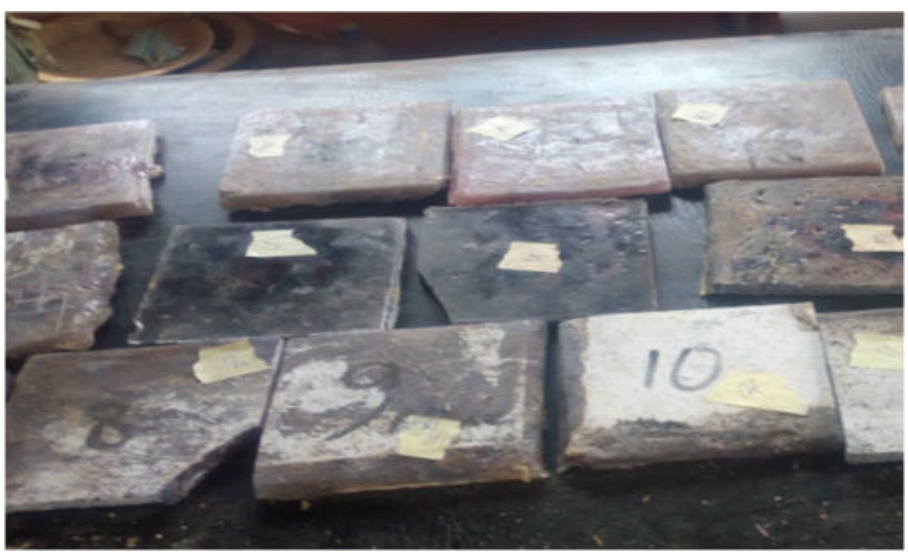

Figure 1a: Photograph of cone calorimeter test sample

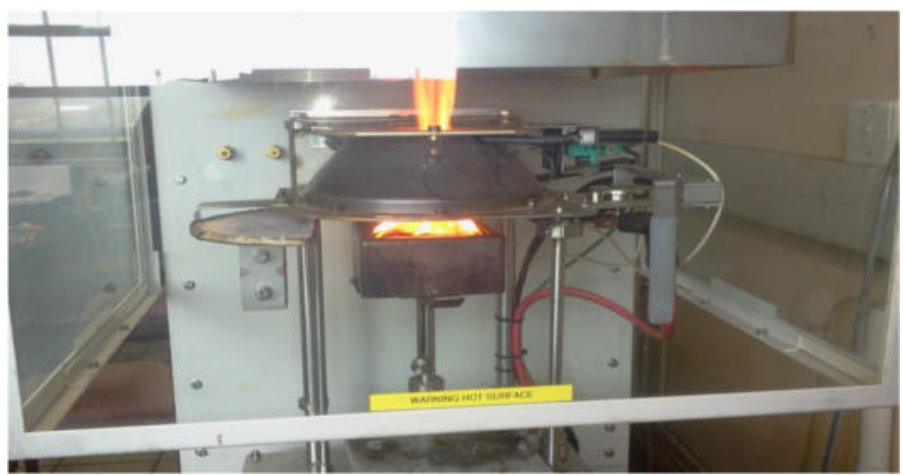

Figure 1b: Photograph of sample flaming inside the cone

\subsection{RESULTS AND DISCUSSION}

\subsection{XRD Analysis}

Figure 2 displayed the XRD spectrum. X-ray diffraction results of AH:BPF and polyester composites were studied, and the results showed that the adoption of $\mathrm{AH}: \mathrm{BPF}$ in polyester had two primary effects: the reinforcement and the nucleating effect. The reinforcement effect increased the bulk crystallinity. The addition of the reinforcement of the matrix changed the characteristics peak position.

The noticeable thing about the XRD patterns is that new peak was found with the addition of AH:BPF. This indicated that, there was strong interaction between BPF:AH and polyester. The presence of new peak was also attributed to the homogenous dispersion of BPF:AH in the matrix. Decrease in intensity corresponding to $\alpha=$ phase at 2 Theta $=9.5^{\circ}$ with increase in $\beta$-phase at 2 Theta $=25^{\circ}$ with BPF:AH loading showed that BPF:AH enhanced the strengthening phase of polyester. 


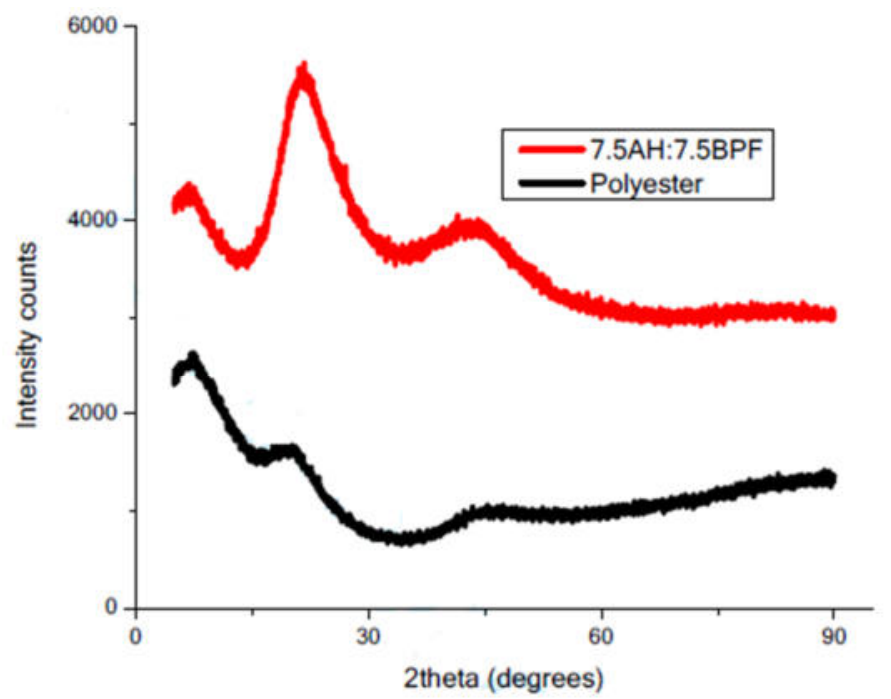

Figure 2: XRD spectrum of the polyester and it composites.

It is evident that the composite is crystalline and dense. The polymer showed broad and less intense bands in the XRD showing that it is semi crystalline. The XRD pattern of composite showed sharp peaks indicating a crystalline structure. It was evident from the XRD studies that there was interaction between the reinforcement and polymer which made the matrix stronger.The polar groups in the polymers interacted with the polar groups in the reinforcement and the interaction decreased the d-spacing in the composite and produced stronger denser composite.

\subsection{TGA/DTA Analysis}

Figure 3 displayed the TGA curves, while figure 4 displayed the derivatives of their weight. The decomposition of the materials was characterized by multiple-stage reactions. A small loss in mass occurred in the first stage when the sample was heated from $50-150^{\circ} \mathrm{C}$, and this was due to the loss of moisture absorbed from the atmosphere together with water formed as a by-product of the cure reaction.

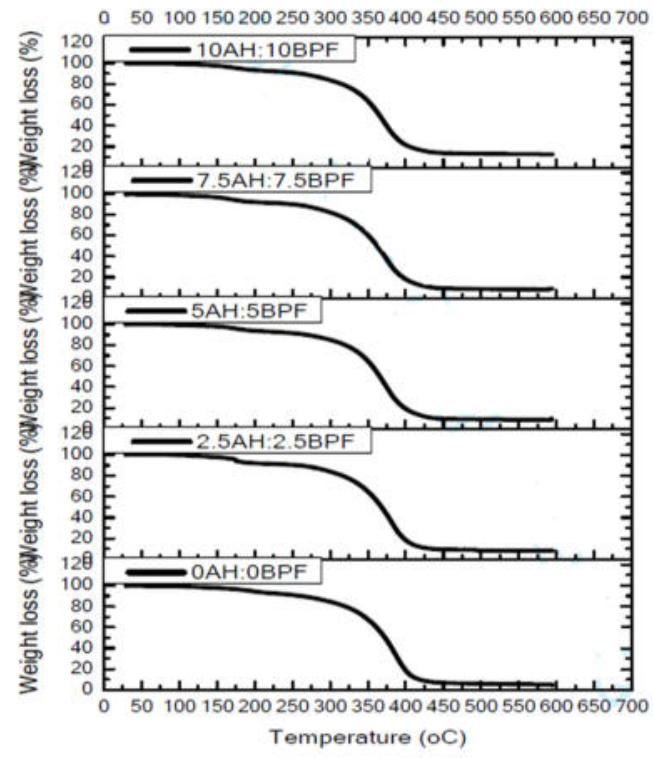

Figure 3: Variation of percentage weight loss with temperature for composites produced with BPF:AH 
The composites produced had higher weight retained or residues. Also it was clearly shown that as the weight percentage of the $\mathrm{AH}$ increased the weight of residues left was higher, for examples the weight of 5.28, 8.274, $8.56,8.85,12.63 \%$ were left at $0.0,2.5: 2.5,5.5,7.5: 7.5$ and 10:1.10wt\% AH:BPF respectively (Table 1)

Table 1: Degradation temperature of composites determined by DTA/TGA

\begin{tabular}{|l|l|l|l|l|l|l|}
\hline Sample & $\begin{array}{l}\mathrm{T}_{10} \text { weight } \\
\text { loss }\end{array}$ & $\begin{array}{l}\mathrm{T}_{50 \text { weight }} \\
\text { loss }\end{array}$ & $\begin{array}{l}\mathrm{T}_{80 \text { weight }} \\
\text { loss }\end{array}$ & $\mathrm{T}_{\max }$ & $\begin{array}{l}\mathrm{T}_{\text {finalweight }} \\
\text { loss }\end{array}$ & $\begin{array}{l}\text { Residues } \\
(\%)\end{array}$ \\
\hline $0 \% \mathrm{AH} \% \mathrm{BPF}$ & 260.84 & 372.48 & 398.4 & 402.0 & 593.57 & 5.28 \\
\hline $2.5 \% \mathrm{AH}: 2.5 \% \mathrm{BPF}$ & 257.23 & 373.122 & 397.64 & 405.0 & 594.07 & 8.274 \\
\hline $5 \% \mathrm{AH}: 7.5 \% \mathrm{BPF}$ & 268.09 & 375.81 & 398.35 & 407.5 & 593.65 & 8.56 \\
\hline $7.7 \% \mathrm{AH}: 7.5 \% \mathrm{BPPF}$ & 347.77 & 382.34 & 406.43 & 409.0 & 593.65 & 8.85 \\
\hline $10 \% \mathrm{AH}: 10 \% \mathrm{BPF}$ & 359.01 & 385.32 & 405.13 & 409.0 & 593.97 & 12.63 \\
\hline
\end{tabular}

It was observed that about $22 \%$ of the weight remained at arround $500^{\circ} \mathrm{C}$ as the the weight percentage additon of $\mathrm{AH}$ increased upto $10 \mathrm{wt} \%$. The higher weight retained for the composites was attributed to the fact that the $\mathrm{AH}$ induced protective barriers against thermal decomposition and retarded the thermal decompositin of polyester $\mathrm{AH}: \mathrm{BPF}$ composite and this phenomenon was as a result of the physical barrier effect of the incorporated microparticles of $\mathrm{AH}$ which acted as mass and heat tranfer barriers.

Figure 4 shows the derivates of wieght with temperatures of the developed composites. It was seen that the decomposition of the composites was an endothermic process that was dominated by random-chain scission of the main polymer chain. There was decomposition temperature shifts to higher temperatures for composites produced with $\mathrm{AH}$.

This behaviour is determiend in the initial stages by scission of highly strained portion of polyester crosslinking with subsequent formation of the free radicals that promote further decomposition and scissors of the polyester backone. As a result, a large amount of low-molecular-weight volatiles $\left(\mathrm{CO}, \mathrm{CO}_{2}\right)$ were released rather than char. The decomposition of polyester/BPF occur as a single - stage process over a similar temperature range althoug this material was completely volalized and did not produce any char residue.

The pronounced single endothermic effects as observed in figure 3 corresponded to the oxidative degradation process and the release of volatile matters. The presence of endothemic effects in the sample were the results of three- intermolecular dehydrogenation, vapourization and solid state decomposition of some additives (e.g plasticizer). This conclusion was confirmed by the decreased mass of the polymer . on the analogy of it was assumed that the total processes burning/degradation of the residual polymer backbone (dehydrogeneaton polyester) took place in this temperature interval of $\left(300-500^{\circ} \mathrm{C}\right)$, which was different for the individual compostes samples in the last temperature interval the mass loss was minimal. This last step (accompanied by the evolution $\mathrm{CO}_{2}$ only) was due to the degradation of the filler material in the composites.

The AH particles acted effectivley as physical barriers and prevented the transport of volatile decomposed products out of the composites during thermal decomposition. It was established that the AH addition on the polyester samples enhanced the stabilization and increased the temperature of maximal decomposition destruction rate. 
O 50100150200250300350400450500550600650700

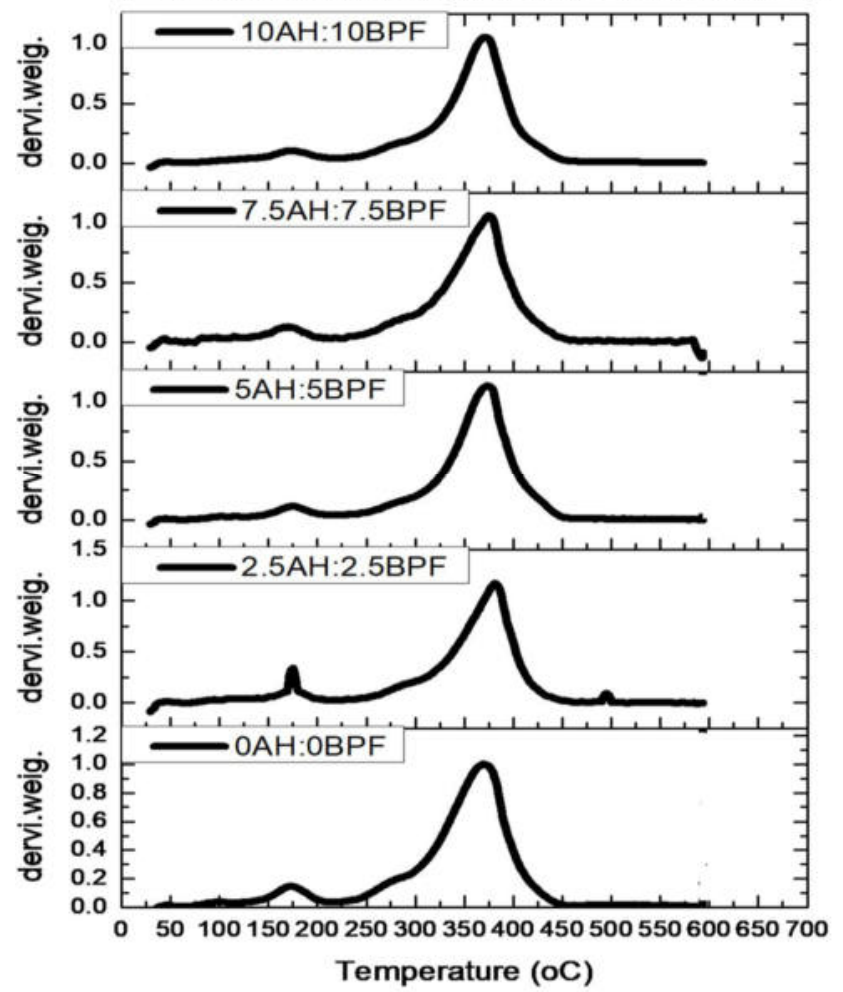

Figure 4: Variation of derivate of weight with temperature for composite produced with AH:BPF

\subsection{Heat Release Rate}

Figure 5 shows the heat release rate (HRR) versus time of the polyester and the composite . From figure 5 it was observed that the peak heat release rate (PHRR) of the composites with AH:BPF decreased progressively with time due to the formation and thickening of a surface char layer that slowed the decomposition reaction rate in the underlying material. The PHRR also declined as a result of the declining resin content in the samples. Eventually the heat released rate became negligible, as the last of the resin matrix was decomposed.

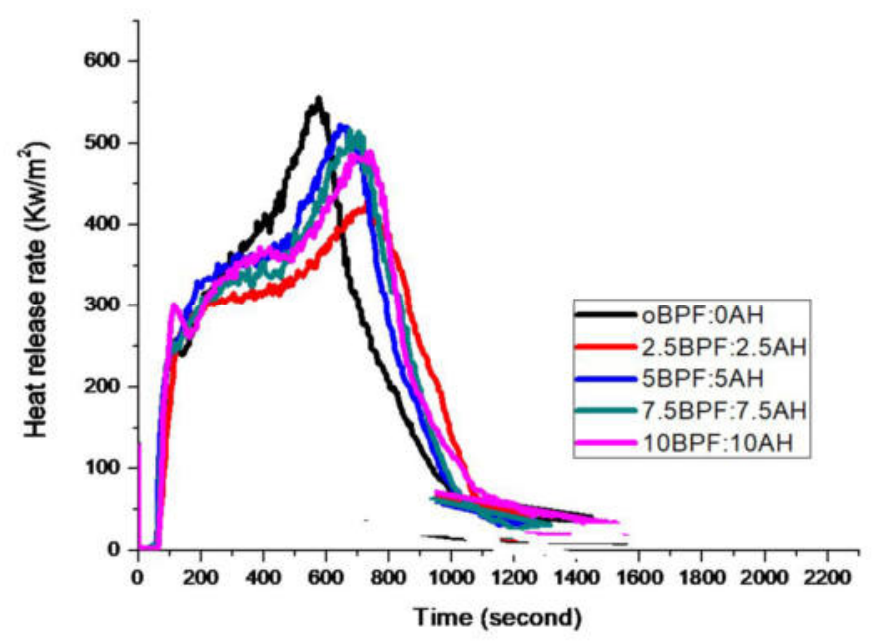

Figure 5: Variation of heat release rate with time for BPF: AH composites 
The heat release rate was substantially higher for polyester (Figure 6 And Table 2). The mean heat release decreased from 223.56 to $210.52 \mathrm{Kw} / \mathrm{m}^{2}$, peak heat release rate decreased from 556.54 to $489.9 \mathrm{w} / \mathrm{m}^{2}$ and total heat release rate decreased from 308.6 to $237.8 \mathrm{MJ} / \mathrm{m}^{2}$ at $0: 0,10: 10 \mathrm{wt} \% \mathrm{BPF}$ :AH respectively (Table 2). The high peak, mean and total heat release rates obtained for polyester were attributed to the fact that polyester at the surface released heat because of its lower temperature of ignition. It is also seen that the heat release rates for the composites containing AH was lower. This was because the temperature of AH yields a much lower amount of flammable volatiles.

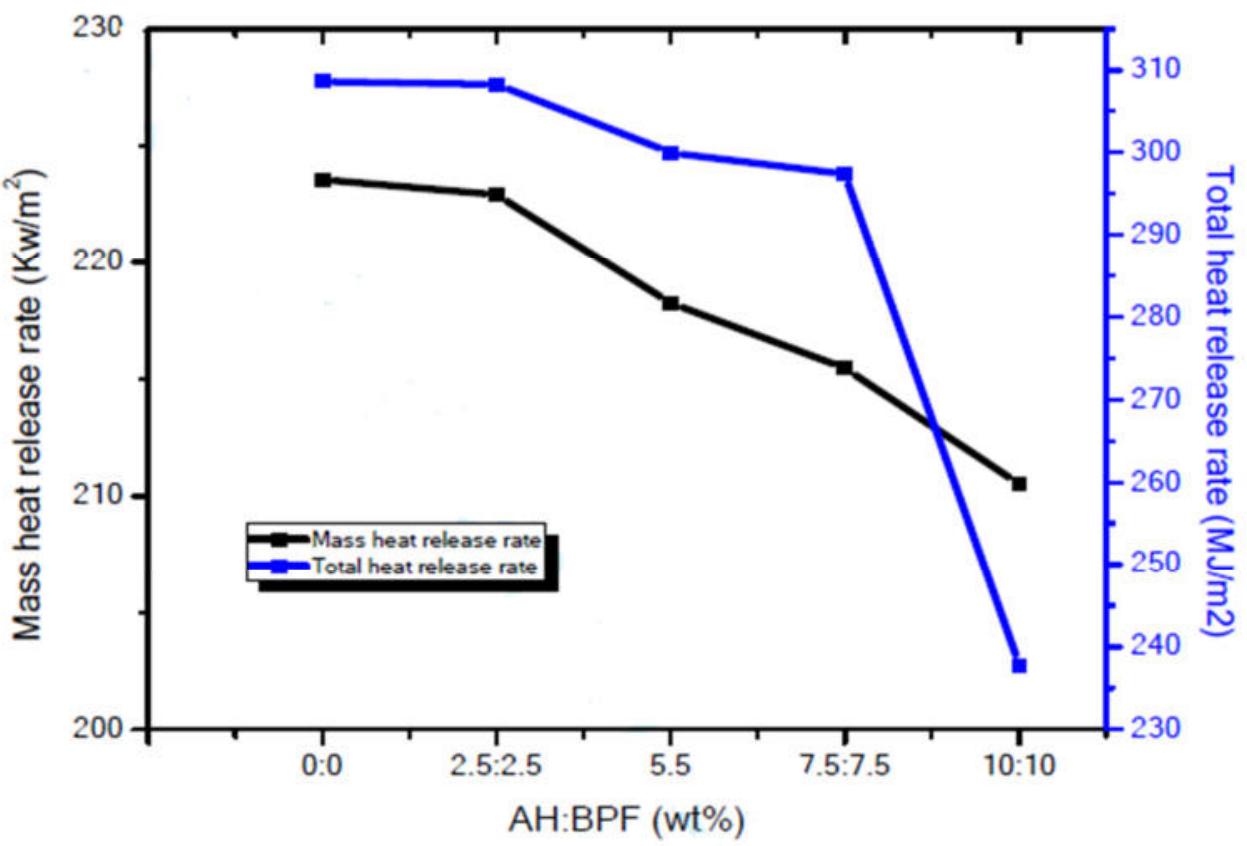

Figure 6: Variation of mass and total heat release rate with wt\%BPF:AH

Table 2: Results of the Cone Calorimeter test

\begin{tabular}{|l|l|l|l|l|l|l|l|l|l|}
\hline & $\begin{array}{l}\text { MHRR } \\
\text { Kw/m }\end{array}$ & $\begin{array}{l}\text { PHRR } \\
\text { Kw/m }\end{array}$ & $\begin{array}{l}\text { THR } \\
\mathrm{MJ} / \mathrm{m}^{2}\end{array}$ & $\begin{array}{l}\text { MASS Loss } \\
\left(\mathrm{g} / \mathrm{m}^{2}\right)\end{array}$ & $\begin{array}{l}\text { TSR } \\
\left(\mathrm{m}^{2} / \mathrm{m}^{2}\right)\end{array}$ & $\begin{array}{l}\text { TSP } \\
\left(\mathrm{m}^{2}\right)\end{array}$ & $\begin{array}{l}\text { TOC } \\
(\mathrm{g})\end{array}$ & $\begin{array}{l}\text { TTG } \\
(\mathrm{s})\end{array}$ & $\begin{array}{l}\text { ETT } \\
(\mathrm{s})\end{array}$ \\
\hline $0 \%$ BPF:0\%AH & 223.56 & 556.54 & 308.6 & 14142.1 & 9378.2 & 82.9 & 206.3 & 64 & 1445 \\
\hline $2.5 \%$ BPF:2.5\%AH & 222.9 & 539.44 & 308.3 & 12274.4 & 8517.8 & 75.3 & 205.3 & 72 & 1455 \\
\hline $5 \%$ BPF:5\%AH & 218.24 & 522.21 & 300.0 & 12364.7 & 8438.5 & 73.4 & 203.5 & 77 & 1550 \\
\hline $7.5 \%$ BPF:7.5\%AH & 215.46 & 515.94 & 297.4 & 12284.5 & 8335.2 & 75.2 & 164.6 & 81 & 1615 \\
\hline $10 \%$ BPF:10\%AH & 210.52 & 489.9 & 237.8 & 12225.5 & 8282.6 & 72.1 & 125.9 & 83 & 1635 \\
\hline
\end{tabular}

$\mathrm{MHR}=$ Mean heat release rate, $\mathrm{PHRR}=$ Peak heat release rate, $\mathrm{THR}=$ Total release rate, $\mathrm{TSR}=$ Total smoke release, $\mathrm{TSP}=$ Total smoke produced, $\mathrm{TTG}=$ Time to ignition, $\mathrm{ETT}=$ End of test time.

\subsection{Mass Loss}

Figure 7 shows the mass loss ratio of the composites. Figure 7 was used to validate the results obtained from the TGA/DTA. It was observed that the mass of the samples decreassed as time increased. But the mass loss of the polyester was higher than that of the composites. From figure 7 it was observed that the mass loss of the composites 
decreases with the wt\%AH addition. This was attributed to the increase in the rate of char which helped to slow down the rate of burning. Similar observation was made in the work of Boulos (2003).

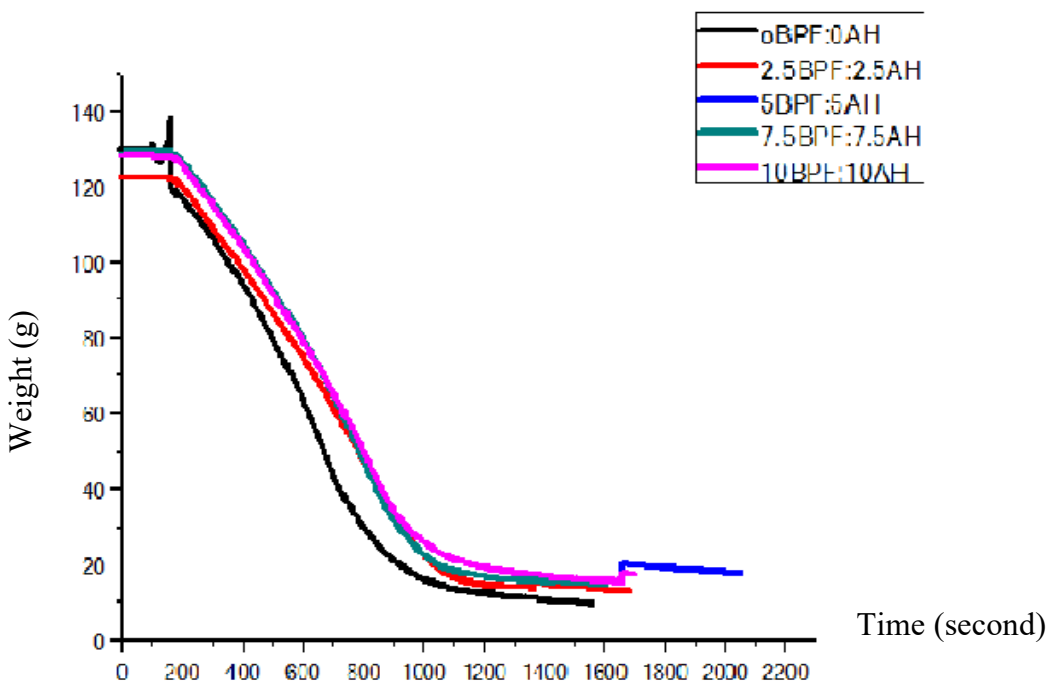

Figure 7: Variation of weight loss with time for $\mathrm{wt} \% \mathrm{BPF}: \mathrm{AH}$ composites

\subsection{Time to Ignition and End of test time}

Figure 8 displayed time to ignition (TTI) and end of test time (ETT). From figure 8 it was observed that the time for ignition for the polyester was shorter than that of the composites. Also the polyester had shorter end of test time, because the polyester burnt faster which resulted to lower end of test time. It was be concluded that the addition of $\mathrm{AH}$ to the polyester resin, slightly delayed the ignition time and reduced PHRR values. In addition, due to the action of the fire retardant, the second peak of the HRR was less pronounced, and the total burning time was increased, indicating that the fire-retarded composite burnt for a longer time with a weaker flame than that of the polyester. However, the TTI and ETT values of AH:BPF composites were increased by the incorporation of the AH. This was the major reason, why the oxygen consumed and smoke releases rate burning was lower for the composites (Table 2), because the BPF:AH composite showed improvement in difficulty to - ignitability.

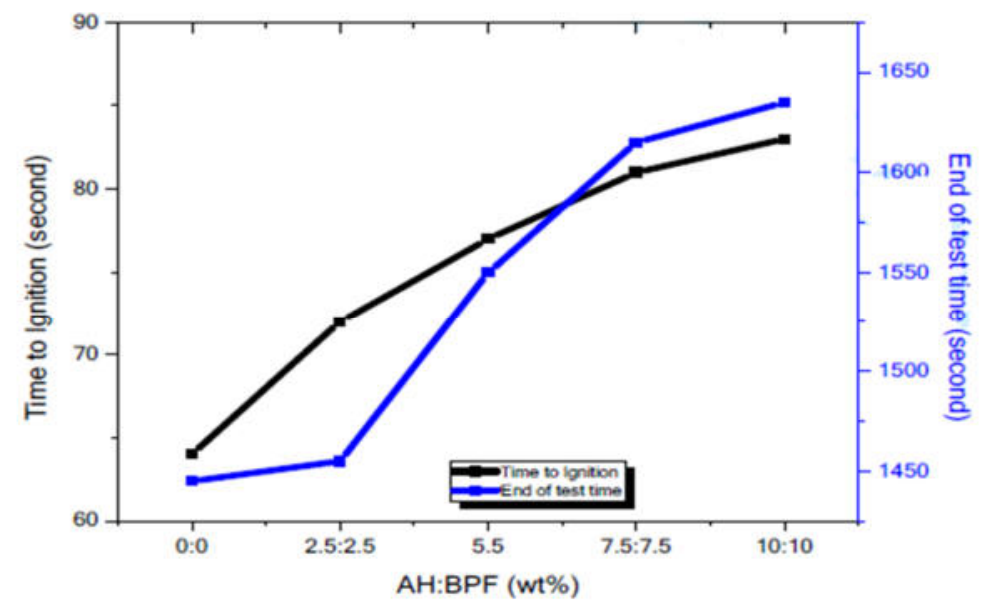

Figure 8: Variation of time to ignition and end of test time with wt $\% \mathrm{BPF}: \mathrm{AH}$ 


\subsection{Photography of the residue left}

Figure 9 shows the photo of the residues after the cone calorimeter experiment. It was observed that the polyester showed little or no residue after burning (Figure 9a). The residue of composite as shown in Figure 9b showed a compact and intumescent char layer, which was the main reason for obtaining better flame retardancy of the composites.

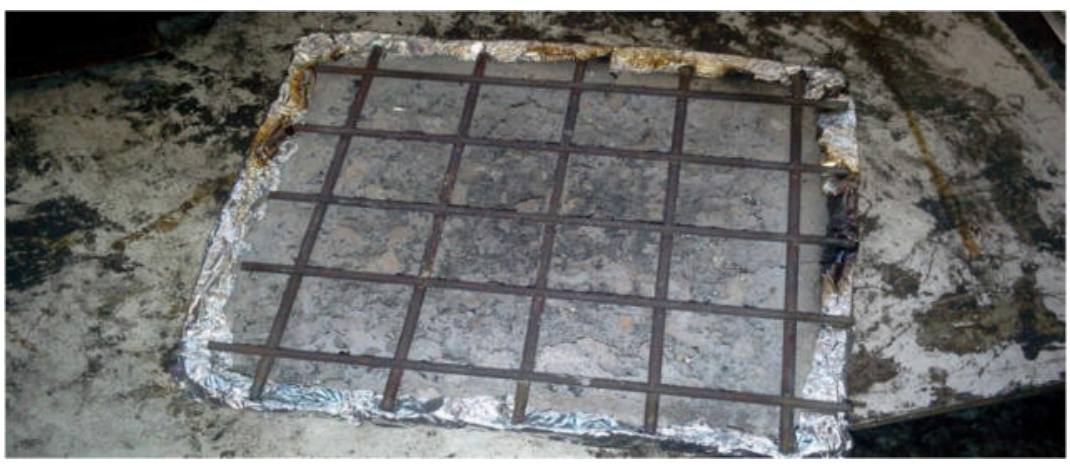

Figure 9a: Photograph of the polyester sample left after fire test

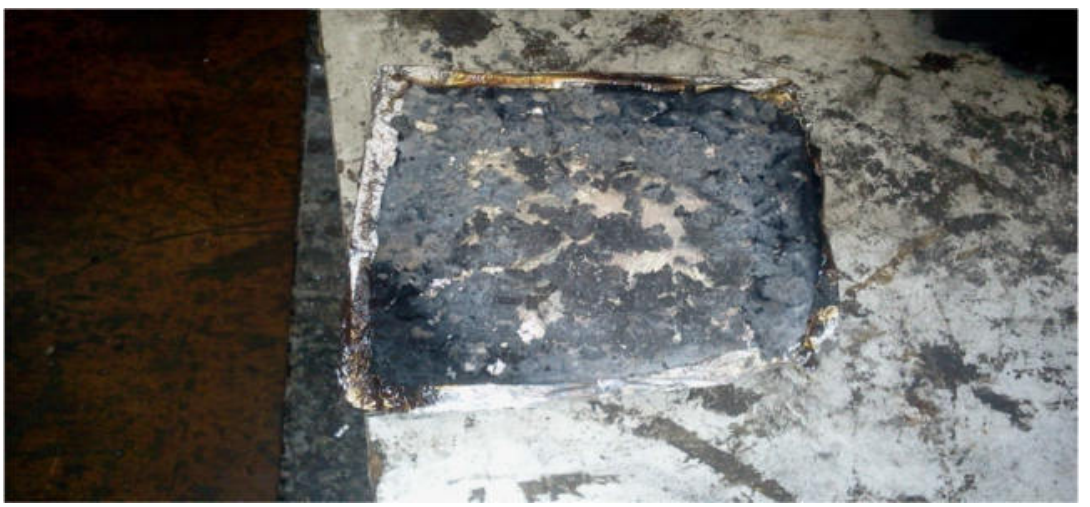

Figure 9b: Photograph of the 7.5\%AH:7.5wt\%BPF sample left after fire test

\subsection{Conclusions}

From the above results and discussion the following conclusions were made:

1. Polyester, aluminium hydroxide particualte $(\mathrm{AH})$ and banana puedostem fibre(BPF) composites was successful produced by hand lay up method.

2. The incorporated AH played a crucial role in improving the thermal stability of the composites by acting as effective physical barrier against the thermal decomposition in the polymer composite.

3. The endothermic peaks shift to higher temperature after the increase of weight of the AH which reflects the improved thermal stability of the composite with $\mathrm{AH}$.

4. This work shows the addition of $10 \mathrm{wt} \% \mathrm{AH}: 10 \mathrm{wt} \% \mathrm{BPF}$ to polyester retard burning by delaying the ignition time by $22.94 \%$, the end of burning time by $13.15 \%$ and reduced the total heat release rate by $29.68 \%$.

\section{REFERENCES}

1. Akash, G., Venkatesha, G., Sreenivas, K.( 2017). A study on flammability and moisture absorption behavior of sisal/coir fiber reinforced hybrid composites, IOP Conf. Series: Materials Science and Engineerin, 19 :203-209 
2. Baljinder, K., John, R., Kawser, C. ( 2015). Flame Retardance and Physical Properties of Novel Cured Blends of Unsaturated Polyester and Furan Resins, Polymers, 7 : 298-315.

3. Ali, F., Roya, M., Mehdi, S., Saeed, J. ( 2015). Developments of Graphene based Polymer Composites Processing Based on Novel Methods for Innovative Applications in Newborn Technologies, Indian Journal of Science and Technology, 8(S9): 38-44,

4. Asuke, F. and Aigbodion, V. (2016) Experiment numerical study of dry sliding wear behavior of epoxy/periwinkles shell particulate composites. Journal of the Chinese Advanced Materials Society. 117

5. Boulos, Y., Laurence, L., Wassef E.; Claude, B.; Bruno, M.(2003). "New Phosphonated Methacrylates: Synthesis, Photocuring and Study of their Thermal and Flame-Retardant Properties", Macromolecular Chemistry and Physics,2003, 204,1842- 1850,

6. Kandare, E., Chukwudolue, C. and Kandola B.(2010). "The use of fire-retardant intumescent mats for fire and heat protection of glass fibre-reinforced polyester composites: Thermal barrier properties.2010IMRI: Journal Articles (Peer-Reviewed) 71: 121-127

7. Abdullah, N., Ahmad, I. and Sains G. (2013). Coconut fibre reinforced polyester composite(CFRPC) by incorporating sodium hydroxide and silane treated coconut fibre Malaysiana, 4: 811-820.

8. Maria, R., Ricciardi, V. A., Michele, G. and Mauro Z. (2014). Thermal decomposition and fire behavior of glass fiber- reinforced polyester resin composites containing phosphate-based fire-retardant additives, Journal of Fire Sciences , 30(4): 318-330.

9. Morgan, A.B.(2006). Flame retarded polymer layered silicate nanocomposites: a review of commercial and open literature systems. Polym. Adv. Technol. 17: 206-217.

10. Mohammad, Z., Kuncoro D., Mujtahid K. and Djoko S.(2018). The properties degradation of exposed GFRP roof AIP Conference Proceedings 1931, 030063 (2018); doi: 10.1063/1.5024122 2009. 69(3-4): 432-437.

11. Sarki, J., Hassan, B., Aigbodion, V. and Oghenevweta, J. (2011).Potential of using Coconut shell fillers in Eco-composites Materials, Journal of Alloy \& Compounds,509: 2381-2385.

12. Nayra, U. and Javier B. (2016). Enhanced flame retardancy of flax biocomposites for the construction market, Journal of Facade Design and Engineering 2016, 67-76

13. Panigrahi, S., Tabil, G., Crerar, W., Sokansanj, J., Ward, T., Powell, A. K. and Braun L.(2002). Application of Saskatchewan grown flax fiber in rotational molding of polymer composites.2002, Paper No. 02-302. CSAE, PO Box 316, Mansonville, QC. J0E 1X0. compounds 509: 2381-2385. 